\title{
Analysis of Reconfigurable Asymmetric Corner ARC Slotted Patch Antenna for Ultrawide and KU Band Application
}

\author{
Manoj Kumar Garg, Jasmine Saini
}

\begin{abstract}
A reconfigurable asymmetric patch antenna with arced corners loaded with a rectangular slot and a $T$ slot on the partial ground used for UWB and $K u$ band applications. The discussion is carried out into three segments. In the first segment, the design of patch antenna proposed asymmetric arcs at the corner, two side slits, and one slot in the middle of the patch while a T-slot integrated on the partial ground plane. This presented antenna covers an impedance bandwidth ranging from $3.0 \mathrm{GHz}$ to $16.2 \mathrm{GHz}$ with a fractional amount of $132 \%$. It is found that a wide band of $3.0 \mathrm{GHz}$ to $10.7 \mathrm{GHz}$ is achieved by using a T-slot on the partial ground plane with a normal rectangular patch while $10.8 \mathrm{GHz}$ to $16.2 \mathrm{GHz}$ is attained by using two corners arcs with two small slits on the patch. The experimental result shows good agreement of 3-dB axial ratio bandwidth and radiation characteristics with the simulated result of the proposed antenna. The second segment proposes an extracted equivalent circuit model for patch and ground plane of corner arc monopole antenna using EM software package in the ADS platform and made a good agreement with the proposed antenna. Finally in the third segment RF PIN diode is embedded in a rectangular slot of the patch which achieves desired frequency shifting in the required band of operation.
\end{abstract}

Keywords: Reconfigurable antenna, T-slot, RF PIN diode, Partial ground, Ultra-Wideband (UWB)

\section{INTRODUCTION}

To obtain a wideband behavior through over whole operating band is an important issue in UWB wireless communications. Consequently, several planar monopoles with different geometries have been experimentally analyzed [1], [2]. Traditionally, ultra-wideband communication systems are required a small and low-cost antenna with omnidirectional radiation patterns and large bandwidth [3]. One of the latest challenges in the designing of the UWB antenna is to impose the need for co-design of antenna structure and its circuit model in the wireless communication system. Many applications require timedomain analysis through time-domain simulator such as SPICE, a general equivalent circuit model of UWB antennas is required. [4].

Revised Manuscript Received on April 13, 2020.

* Correspondence Author

Manoj Kumar Garg*, Department of Electronics and Communication, Jaypee Institute of Information Technology, Noida, India. gargnitoo@gmail.com

Jasmine Saini, Department of Electronics and Communication, Jaypee Institute of Information Technology, Noida, India gargnitoo@gmail.com

(C) The Authors. Published by Blue Eyes Intelligence Engineering and Sciences Publication (BEIESP). This is an open access article under the CC BY-NC-ND license (http://creativecommons.org/licenses/by-nc-nd/4.0/)
Regarding impedance and admittance matching, various equivalent circuit models of rectangular microstrip patch antenna are given. In [5]. An EM antenna based circuit refinement method having a narrow band who augmented with a macro model is discussed and de-generated a foster canonical form. A nonlinear curve fitting optimization method for calculating the extract parameters value of patch antenna is used [6]. In [7], An LC equivalent model related to its physical dimensions of a rectangular microstrip patch antenna is shown. And model geometry of the patch is extracted by using a cavity model. Most of the microstrip patch antennas are presented with their parallel RLC circuits in the [8]. A lot of active research has been done to calculate the RLC values in the circuit model [8]-[11]. The radiating element of the UWB patch antenna has been expressed as several parallel RLC circuits in series due to its matching bandwidth and resulting from several adjacent resonances [12]. A large band of $2.9 \mathrm{GHz}$ to $14.1 \mathrm{GHz}$ in a small square monopole antenna using an inverted $\mathrm{T}$ shaped slot is achieved [13]. This paper proposes a reconfigurable asymmetric corner arcs patch antenna with a $\mathrm{T}$ slot on the partial ground plane for ultra-wide and $\mathrm{Ku}$ band applications. The proposed antenna covers a wide impedance bandwidth of $13 \mathrm{GHz}$ within the range of $3.2 \mathrm{GHz}$ to $16.2 \mathrm{GHz}$. An RF PIN diode is used to achieving a reconfigurable feature of the antenna. The paper is organized into three sections: antenna design consideration is presented in Section II while section III brief about the extracted model of the patch and the reverse plane and results and discussion is given in the last section (IV).

\section{ANTENNA DESIGN CONSIDERATION}

Fig. 1 shows the geometry of the proposed antenna where its top view, back view, and embedded RF PIN diode is to be considered. The basic structure of the antenna consists of the rectangular patch, defected ground (monopole) and double step microstrip feed. The proposed antenna is printed on Rogers RT Duroid 5880 having a thickness of $1.6 \mathrm{~mm}$, dielectric constant $\left(\epsilon_{\mathrm{r}}\right)$ of 2.2 and loss tangent of 0.0009 is to be taken. A double step feed line is employed for exciting the patch antenna. A slot on the partial ground plane, two edge slits, and one slot as the middle of the patch are taken to improve the bandwidth of the proposed antenna. 
The dimensions of slits and slots are optimized for large bandwidth. There are two circular arcs on patch corners and their radius is optimized for achieving the circular polarization. In addition to this, a PIN diode (BAR50-02) is placed into the rectangular slot on the patch which can be turned ' $\mathrm{ON}$ ' and turned 'OFF' using dc bias voltage. It is observed that a frequency band is completely shifted from its original position when the diode is turned $\mathrm{ON}$ with suitable dc bias. Because of this shifted frequency band, features such as re-configurable behavior and compactness in this antenna could be achieved. The patch and the ground plane of asymmetric corner arcs monopole fabricated antenna with T-slot are presented in fig. 2 (a) and 2 (b). A PIN diode is embedded in the middle of a rectangular slot which is shown in fig. 1 (c). The dimension and its values of the proposed antenna are shown in Table I.

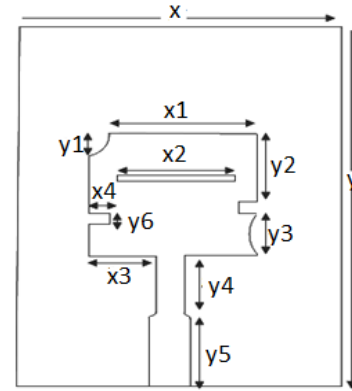

(a)

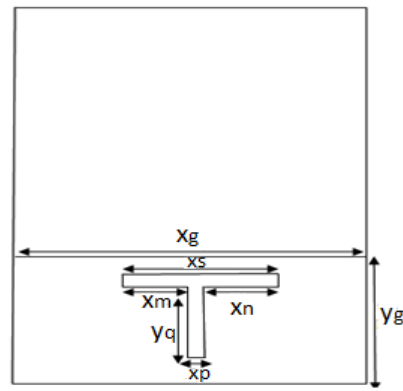

(b)

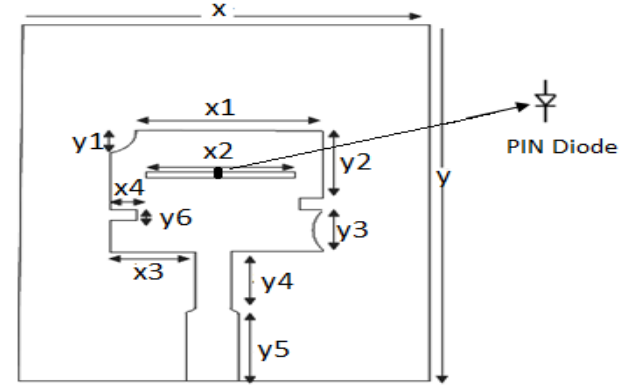

(c)

Fig. 1. The geometry of the proposed antenna with its (a) Top view (b) Bottom View (c) Embedded RF PIN diode (a)

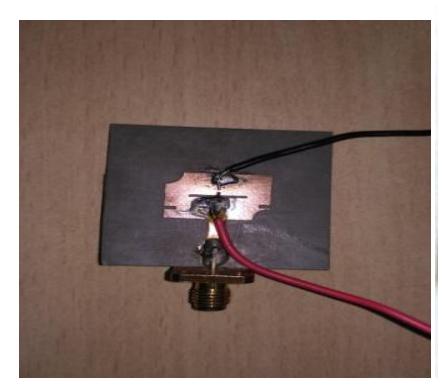

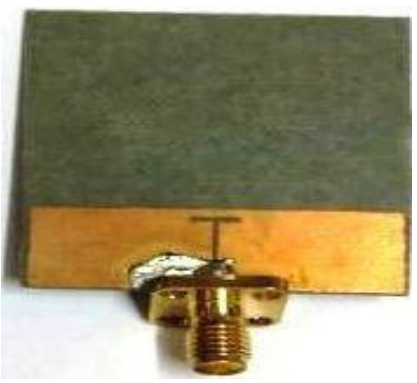

(b)
Fig. 2. Fabricated antenna (a) Front with PIN diode (b) Ground

\section{ANTENNA EQUIVALENT MODEL}

\section{A. Patch equivalent circuit}

The rectangular patch equivalent circuit is described as the combination of resistance $\mathrm{R}$, inductance $\mathrm{L}$ and capacitance $\mathrm{C}$ connected in parallel as shown in fig. 3(a). The values of these components can be calculated by using equation 1 [14].
$\mathrm{R}=\frac{\mathrm{Q}_{r}}{w C}, \mathrm{~L}=\frac{1}{w^{2} C} \quad$ and $\mathrm{C}=\frac{L W \varepsilon_{0} \varepsilon_{e}}{2 h} \cos ^{-2}\left(\frac{\pi y_{n}}{L}\right)$

Where $\mathrm{L}$ and $\mathrm{W}$ are the length and width of the rectangular patch respectively, $\mathrm{y}_{\mathrm{n}}$ is a feed point location and $\mathrm{h}$ is the thickness of the substrate

$\mathrm{Q}_{\mathrm{r}}=\frac{c \sqrt{\varepsilon_{e}}}{4 f h}$

Table-I: Dimensions of the proposed patch antenna

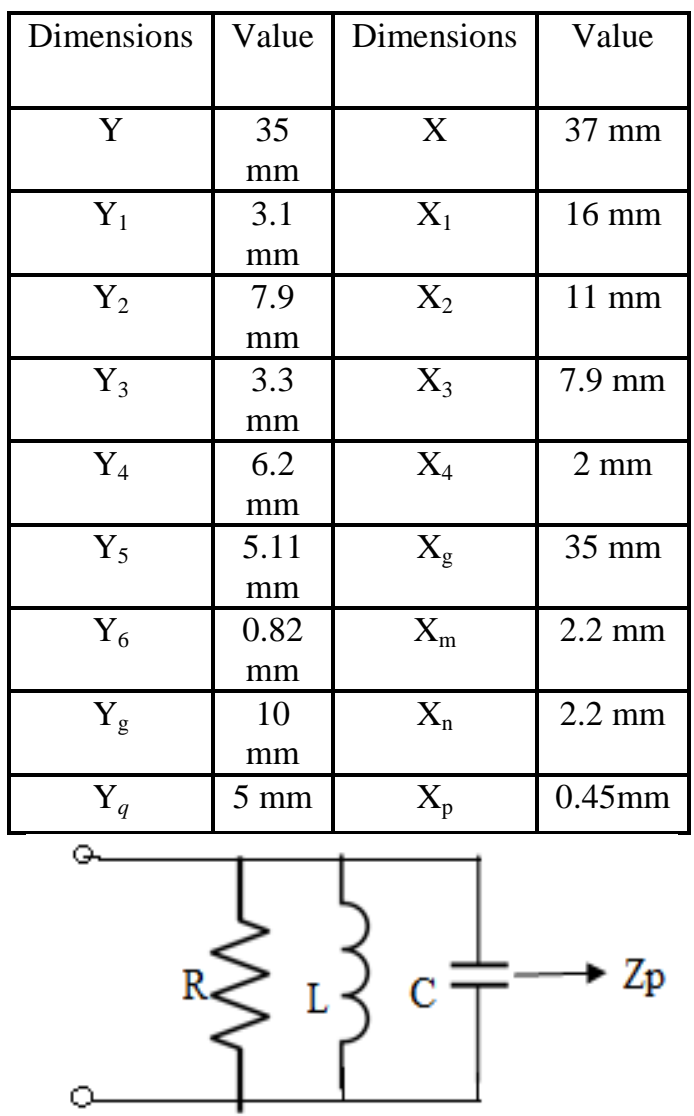

(a)

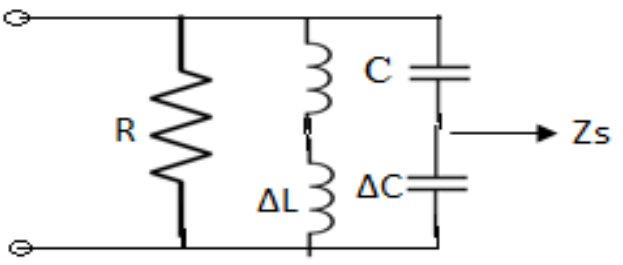

(b)

Fig. 3. (a) Patch Equivalent circuit (b) Patch with slits Equivalent circuit

The impedance of the patch can be calculated as-

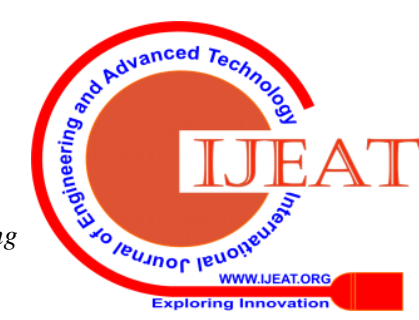




$$
\mathrm{Zp}=\frac{1}{\left(\frac{1}{R}+\frac{1}{j w L}+j w C\right)}
$$

In proposed work slits are used so another current flow in the patch which causes the antenna to resonate on other frequency and bandwidth increases. Figure 3(b) shows the equivalent circuit of the slit and its impedance is represented as Zs. Extra inductance $\Delta \mathrm{L}$ and capacitance $\Delta \mathrm{C}$ is added with an inductance (L) and capacitance (C) of patch antenna as shown in figure 3(b) [14]. One rectangular slot is taken in the middle of the patch and its equivalent circuit is shown in figure 4(a). Rectangular slot impedance $\mathrm{Zr}$ is given in equation 4 [15]. A combined equivalent circuit of slit and slot loaded patch is shown in figure 4(b) where $\mathrm{Zm}$ represents mutual inductance between $\mathrm{Zs}$ and $\mathrm{Zp}$.

$$
\mathrm{Zr}=\mathrm{Rr}+\mathrm{j} \mathrm{Xr}
$$

Where:

$$
\begin{aligned}
& \mathrm{Rr}=60 \mathrm{Y}+\ln (\mathrm{kL})+\frac{1}{2} \sin (\mathrm{kL})[\mathrm{Si}(2 \mathrm{~kL}) 2 \mathrm{Si}(\mathrm{kL})]+ \\
& \frac{1}{2} \cos (\mathrm{kL}) \mathrm{Y}+\ln \frac{k L}{2}+\mathrm{Ci}(2 \mathrm{~kL}) 2 \mathrm{Ci}(\mathrm{kL}) \\
& \text { and }
\end{aligned}
$$

$\mathrm{Xr}=30 \cos 2 \alpha\{2 \mathrm{Si}(\mathrm{kL})+\cos (\mathrm{kL})[2 \mathrm{Si}(\mathrm{kL})-\mathrm{Si}(2 \mathrm{~kL})-$ $\left.\sin (\mathrm{kL})]\left[2 \mathrm{Ci}(\mathrm{kL})-\mathrm{Ci}(2 \mathrm{~kL})-\mathrm{Ci}\left(\frac{2 \mathrm{kWs} 2}{\mathrm{~L}}\right)\right]\right\}$

Where $\mathrm{Y}$ is Euler's constant, $\mathrm{k}$ is propagation constant in free space, $\mathrm{Si}$ and $\mathrm{Ci}$ are the sine and cosine integrals given as-

$\operatorname{Si}(x)=\int_{0}^{x} \frac{\sin (x)}{x}$

$\mathrm{Ci}(\mathrm{x})=-\int_{x}^{\infty} \frac{\sin (x)}{x}$

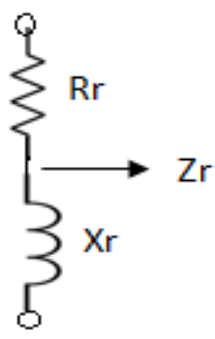

(a)

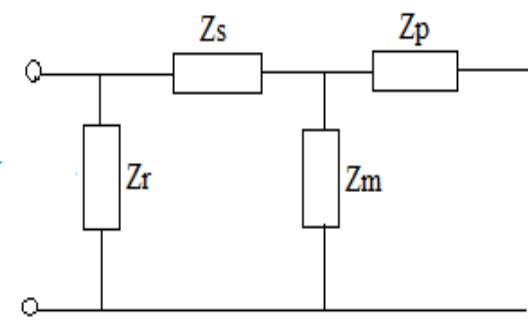

(b)
$(4$

Fig. 4. (a) Equivalent circuit of slot (b) Equivalent circuit of the patch with slit and slot.

After connecting two steps microstrip line to patch antenna for signal feeding purpose, the total patch equivalent circuit is shown in figure 5 . In figure $5, \mathrm{~L}_{14}$ and $\mathrm{L}_{15}$ are the inductance of a two-step feeding line corresponding to its length $\mathrm{y}_{4}$ and $\mathrm{y}_{5}$ respectively.

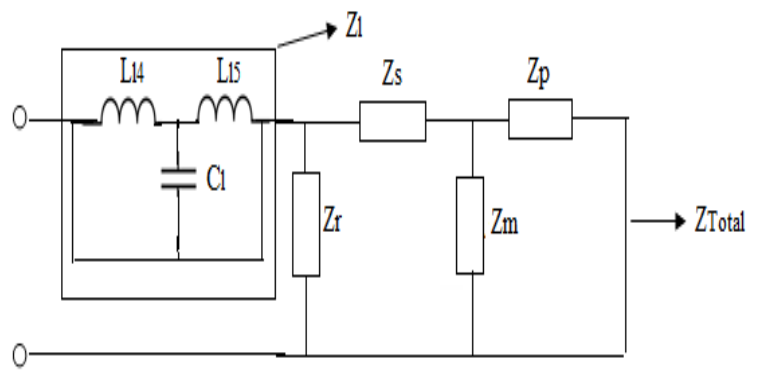

Fig. 5. Total patch equivalent circuit

\section{B. Ground plane equivalent circuit}

The extracted inductor-capacitor equivalent circuit of the ground plane is given in figure 6 . A reverse plane of the antenna involves a T-slot on the partial conducting plane and achieved a wide band from $3.2 \mathrm{GHz}$ to $10.8 \mathrm{GHz}$ when evaluated. To extract the RLC equivalent model for the reverse plane of the antenna, the electromagnetic software package is used in the advanced design system (ADS) platform. In the equivalent circuit of the partial ground plane, an inductor L1 in series and two capacitors C1 and C2 in parallel are connected with a circuit consists of an LC parallel combination. The equivalent circuit provided (44+ j $0.21) \Omega$ impedance of partial ground plane structure which about

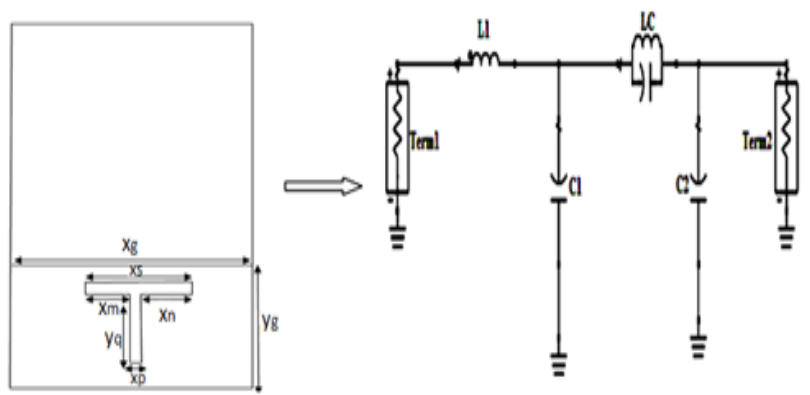

Fig. 6: Extracted equivalent circuit of T-slotted partial ground plane

equal to $50 \Omega$. Due to fine impedance matching, the equivalent circuit of partial ground attains a wideband from $3.2 \mathrm{GHz}$ to $10.8 \mathrm{GHz}$ as shown in figure 7 . It is clear at the point of observation that the extracted model achieves wide impedance bandwidth and made a good agreement with the original geometry of the proposed antenna.

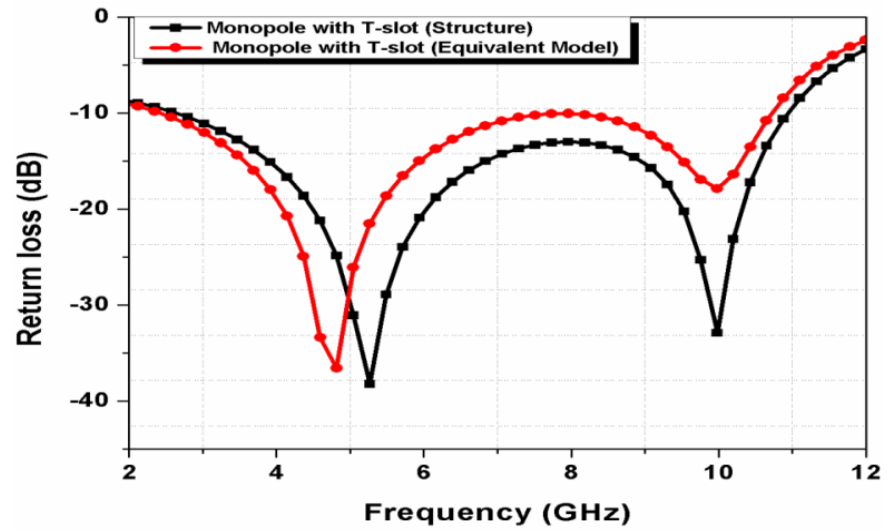

Figure 7: Return loss comparison graph between partial ground structure and its equivalent model

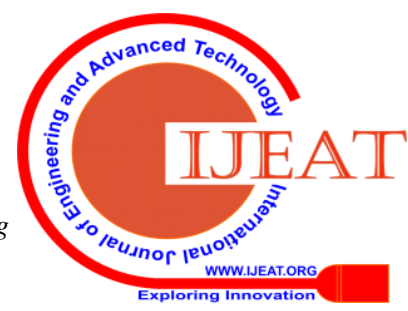




\section{RESULTS AND DISCUSSION}

This section includes simulation and measured results of the proposed antenna which describes the performance parameters such as return loss, gain, axial-ratio bandwidth, and radiation pattern. It is interesting to note here, the proposed antenna achieved two major wide bands (UWB and Ku-band) along with its circuit analysis. The performance of the antenna is commencing with return loss variation without PIN diode and which is shown in figure 8 . Results show that by taking the asymmetric corner arcs with two edge slits on the patch, wide impedance bandwidth ranging from $3 \mathrm{GHz}$ to $16.2 \mathrm{GHz}$ is obtained. It is due to cut two edge slits on the patch where current is concentrated only in one direction on the top arc while in both directions (clockwise and anticlockwise) on the bottom arc and which can be seen as a dark circle in figure 9. The surface current distribution pattern at $10 \mathrm{GHz}$ with and without PIN diode is observed for the bandwidth and which is illustrated in figure 9(a) and figure 9(b) respectively. In figure 10, the reconfigurable feature is found when the RF PIN diode is embedded in the middle slot on the patch. When PIN diode turns $\mathrm{ON}$, the frequency band is shifted to the right side by $1.5 \mathrm{GHz}$. In addition to this, one more resonant frequency at

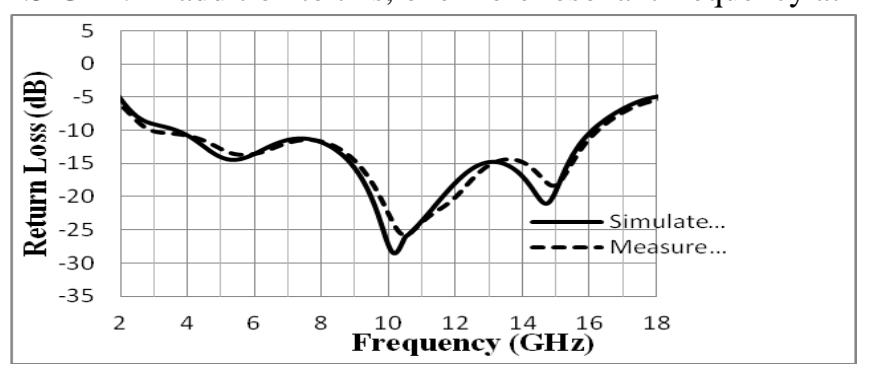

Figure 8: Simulated and measured return loss of antenna without PIN diode

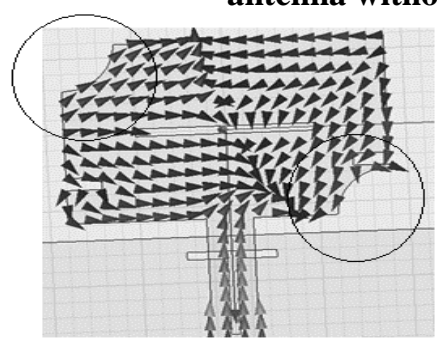

(a)

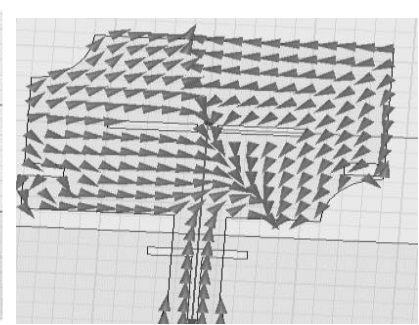

(b)
Fig. 9. Surface Current distribution at $10 \mathrm{GHz}$ (a) PIN diode 'OFF' (b) PIN diode ' $O N$ '

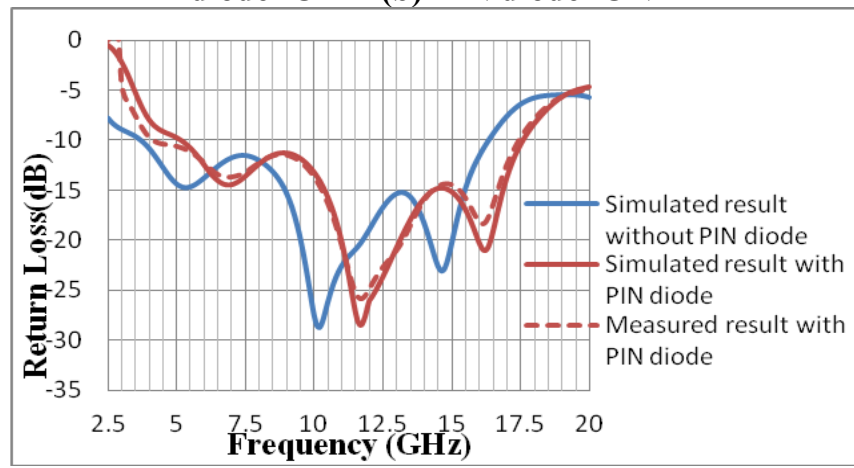

Fig. 10. Comparison of the proposed antenna between the PIN diode ' $O N$ ' and PIN diode 'OFF'
$5.2 \mathrm{GHz}$ is observed within the desired band of operation and this is due to the impedance of PIN diode. The measurement of return loss is done by using 8722ES Key sight VNA $40 \mathrm{GHz}$. A gain of the proposed antenna with and without PIN diode is shown in figure 11. The highest peak gain of $10 \mathrm{~dB}$ at $11.8 \mathrm{GHz}$ is observed within the desired band of operation when the PIN diode is turned ' $\mathrm{ON}$ '. Figure 12 is shown simulated and measured the axial ratio of the proposed antenna where less than 3-dB axial ratio

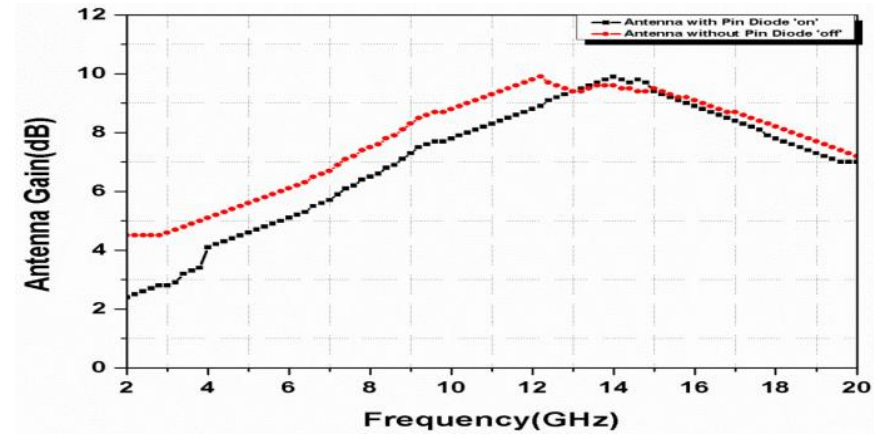

Figure 11: Variation of gain with frequency

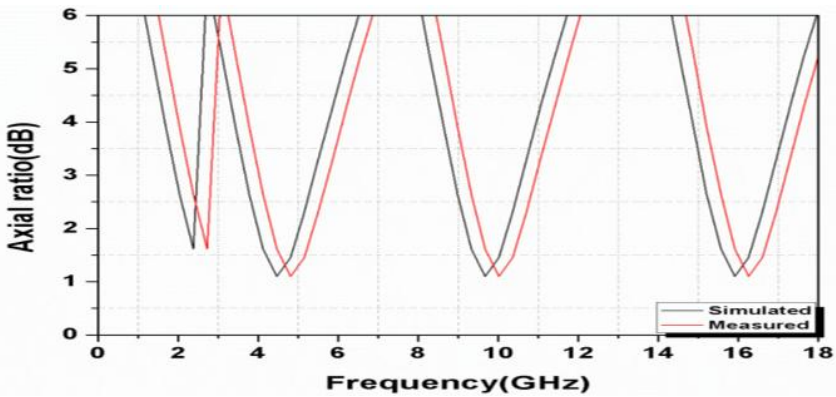

Figure 12: Axial ratio versus frequency

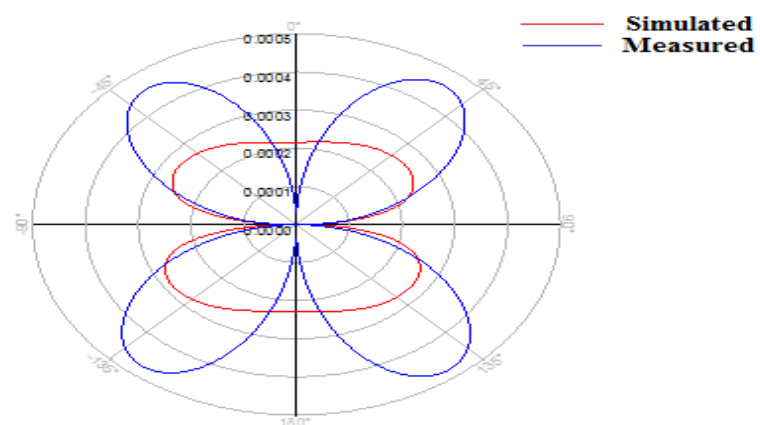

(a)

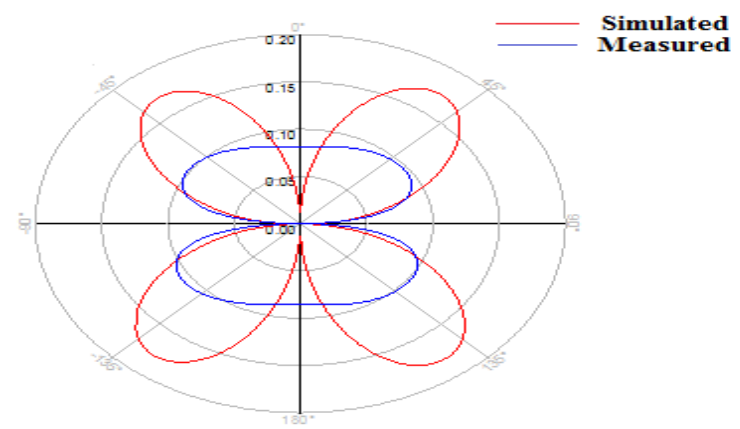

(b)

Figure 13: Radiation pattern at 5.2GHz (a) $\varphi=90^{\circ}$ and $\theta=0^{0}$ for electric (b) $\varphi=90^{\circ}$ and $\theta=0^{0}$ for magnetic
Blue Eyes Intelligence Engineering \& Sciences Publication (C) Copyright: All rights reserved.

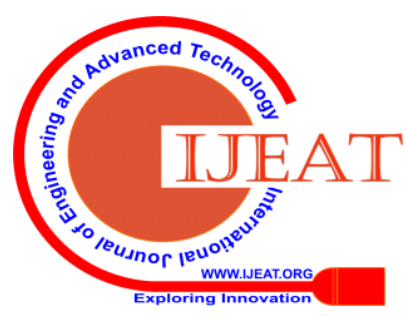


bandwidth is succeeded. The axial ratio values are $1.7 \mathrm{~dB}$ at $2.5 \mathrm{GHz}, 1.2 \mathrm{~dB}$ at $4.2 \mathrm{GHz}, 1.2 \mathrm{~dB}$ at $9.8 \mathrm{GHz}$ and $1.2 \mathrm{~dB}$ at $15.5 \mathrm{GHz}$ respectively.

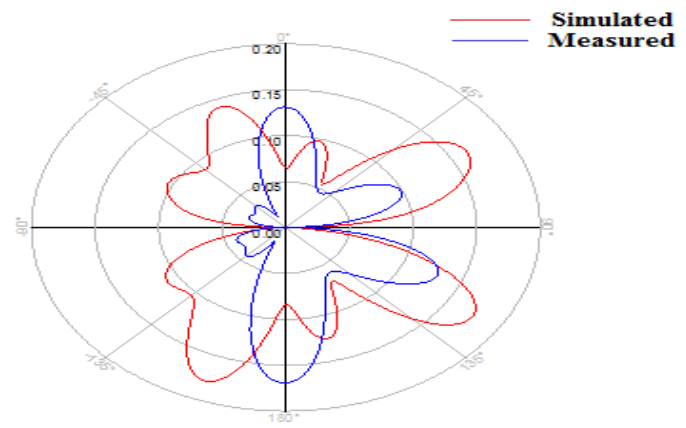

(a)

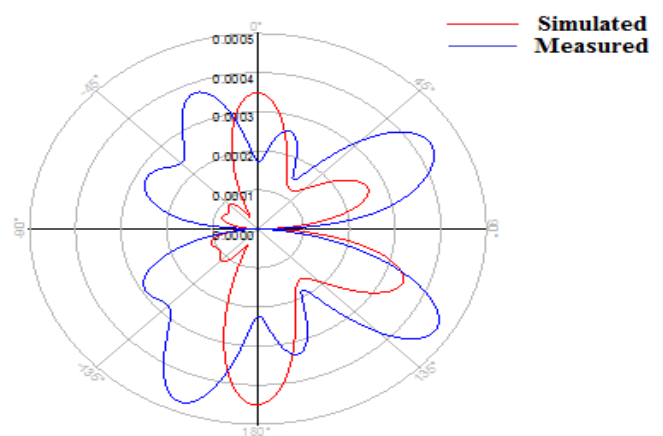

(b)

Figure 14: Radiation pattern at $10 \mathrm{GHz}$ (a) $\varphi=90^{\circ}$ and $\theta$ $=0^{0}$ for electric (b) $\varphi=90^{\circ}$ and $\theta=0^{\circ}$ for magnetic

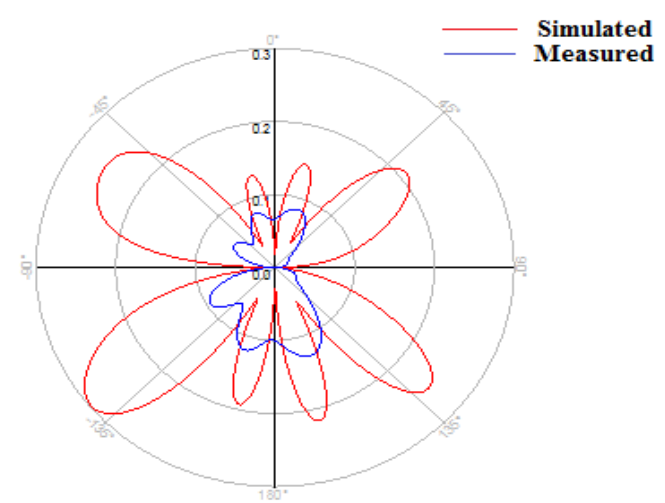

(a)

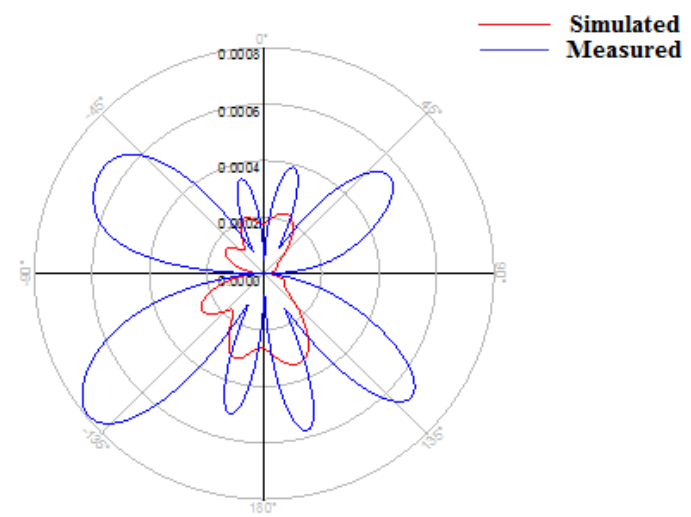

(b)

Figure 15: Radiation pattern at $15 \mathrm{GHz}$ (a) $\varphi=90^{\circ}$ and $\theta$ $=0^{0}$ for electric (b) $\varphi=90^{\circ}$ and $\theta=0^{0}$ for magnetic.
The simulated and measured axial ratio made a good correlation with each other. The far-field radiation pattern of the proposed antenna at $5.2 \mathrm{GHz}, 10 \mathrm{GHz}$ and $15 \mathrm{GHz}$ are shown in figure 13, figure 14 and figure 15 respectively. The radiation pattern is observed for electric as well as a magnetic field when phi $=90^{\circ}$ and theta $=0^{\circ}$ are considered. The far-field pattern at $5.2 \mathrm{GHz}$ showing omnidirectional electric and magnetic fields with a figure of eight shapes which can be seen in figure 13 . While in figure 14, major lobes are diverted beyond $-45^{\circ}$ and $-135^{\circ}$ and make radiation in the positive and clockwise direction. Figure 15 shown patterns at $15 \mathrm{GHz}$ where major lobes show an again omnidirectional pattern with less magnitude. All radiation patterns are measured using a semi-anechoic chamber stepup where simulation and measured results are made a good correlation with each other.

\section{CONCLUSION}

In this paper, a frequency-reconfigurable, wide bandwidth, high gain monopole patch antenna has been presented. The proposed antenna is capable to cover both UWB and $\mathrm{Ku}$ bands. Excitation of the antenna is made through the wave port and used double step microstrip feed which provides better impedance matching. By adding slits and slots on the patch and ground, a wide bandwidth has been achieved. An equivalent circuit model of the patch and partial ground plane is extracted and analyzed which shows a good agreement in results. An RF PIN diode is used in the middle of patch slots to shift the frequency band.

\section{REFERENCES}

1. M. J. Ammann, "Impedance bandwidth of the square planar monopole", Microwave Optical Technology Letters 24, pp.185-187, 2000.

2. J.A. Evans and M.J. Amunann, "Planar trapezoidal and pentagonal monopoles with impedance bandwidths in excess of 10:1", IEEE Antennas and Propagation Society International Symposium 3, pp. 158-161,1999.

3. H. Schantz and Seong-Youp Suh, "The Art and Science of UltraWideband Antennas", $2^{\text {nd }}$ Edition, Artech House, Boston, 2005.

4. Y. Wang, J. Li, and L.-X. Ran, "An equivalent circuit modeling method for ultra-wideband antennas", Progress in Electromagnetic Research 82, pp. 433-445, 2008.

5. S.B.T. Wang, A.M. Niknejad and R.W. Brodersen, "Circuit modeling methodology for UWB Omnidirectional small antennas", IEEE Journal on Selected Areas in Communications, Vol. 24, Issue. 4, pp. 871-877, April 2006.

6. Manoj Garg, Jasmine Saini, Sandeep Kumar, B.K. Kanaujia, Gunjan Mittal. "Extracted LC model of monopole antenna with T-slot for UWB application", 2016 International Conference on Signal Processing and Communication (ICSC), 2016

7. F. Abboud, J.P. Damiano, and A. Papiernik, "Abboud, F.: Simple model for the input impedance of coax-fed rectangular microstrip patch antenna for CAD", IEE Proceedings H-Microwaves Antennas and Propagation, Vol. 135, Issue 5,pp.323-326, Oct. 1988

8. Oon Kheng Heong et al, "Generalized equivalent circuit model for ultra-wideband antenna structure with double steps for energy scavenging," IOP Conf. Ser.: Earth Environ. Sci. 16 012073, 2013.

9. M. Edimo, K. Mahdjoubi, and A. Sharaiha, "Simple circuit model for coax-fed stacked rectangular microstrip patch antenna"., IEE Proceedings-Microwaves, Antennas Propagation, Vol. 145, Issue. 3 , pp. 268-272, Jun 1998 ).

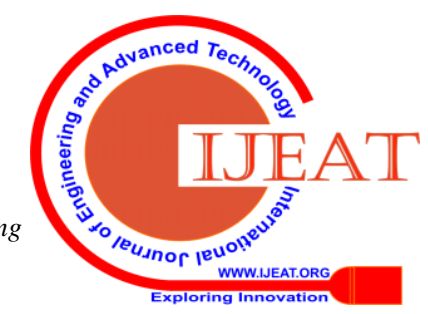


10. R.W. Dearnley and A.R.F. Barel, "A comparison of models to determine the resonant frequencies of a rectangular microstrip antenna", IEEE Transactions on Antennas and Propagation, Volume. 37, Issue. 1, pp.114-118, Jan 1989

11. N. M. Martin, "Improved cavity model parameters for calculation of resonant frequency of rectangular microstrip antennas", Electronics Letters, Vol.24, Issue. 11, pp.680-681,6 May 1988.

12. Qing-Xin Chu and Ying-Ying Yang, "A compact ultra-wideband antenna with $3.4 / 5.5 \mathrm{GHz}$ dual band-notched characteristics", IEEE Transactions on Antennas and Propagation, Vol.56, Issue.12, pp, 3637-3644, Dec. 2008.1

13. M. Ojaroudi, Sh. Yazdanifard, N. Ojaroudi, and M. NaserMoghaddasi, "Small Square Monopole Antenna with Enhanced Bandwidth by Using Inverted T-Shaped Slot and Conductor-Backed Plane", IEEE Transactions on Antennas and Propagation, Vol. 59, Issue.2, pp. 670-674 Feb 2011.

14. Mohammad Aneesh, Jamshed A. Ansari, Ashish Singh, Kamakshi, and Saiyed S. Sayeed, "Analysis of Microstrip Line Feed Slot Loaded Patch Antenna Using Artificial Neural Network", Progress In Electromagnetics Research, Vol. 58, pp.35 - 46, 2014.

15. J. A. Ansari, N. P. Yadav, P. Singh, and A. Mishra, "Compact Half USlot Loaded Shorted Rectangular Patch Antenna For Broadband Operation”, Progress In Electromagnetic Research M, Vol. 9, pp. 215226, 2009

\section{ACKNOWLEDGE}

Authors would like to thank the Department of Electronics and Communication Engineering, JIIT Noida and AIT New Delhi for providing the necessary facility to measure the antenna

\section{AUTHORS PROFILE}

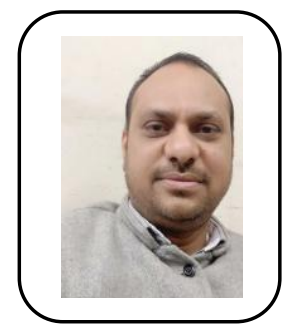

Mr. Manoj Kumar Garg has done his B.Tech in Electronics and Comm. Engineering from Uttar Pradesh Technical University and M. Tech in Digital Communication from Rajasthan Technical University. He is currently pursuing his Ph.D. in the department of Electronics and Communication Engineering, Jaypee Institute of Information Technology, Noida, India. He is currently working in the area of microstrip reconfigurable antenna.

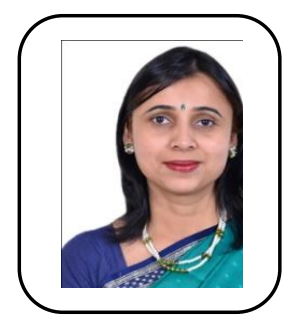

Dr. Jasmine Saini (M'18) has done her Ph.D. in the area of Gyro-Traveling Wave Tubes in 2014. She has done her M.E. from Thapar University, Patiala in 2004. She is currently an Associate Professor with the Department of Electronics and Communication Engineering, Jaypee Institute of Information Technology, Noida, India. She is currently a Member of IEEE. Her current research interest is in the area of Gyro-devices, microstrip patch antenna, Bloch Surface waves.

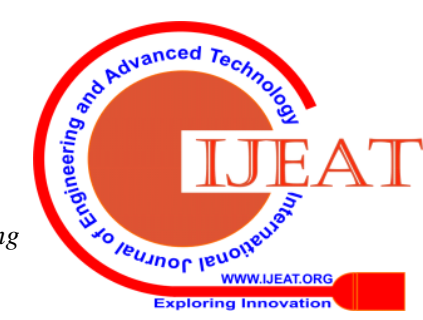

